\title{
DAS PALAVRAS E DA MÚSICA: \\ INTERSECÇÕES NA OBRA DE FERNANDA DE CASTRO ${ }^{1}$
}

Helena Marinho é pianista, professora auxiliar da Universidade de Aveiro e investigadora do INET-MD. Os seus interesses de pesquisa centram-se nas áreas dos estudos em performance musical, e história da música portuguesa nos séculos XX e XXI. Lidera presentemente um projecto de investigação financiado por fundos nacionais e europeus sobre música e mulheres em Portugal nos séculos XX e XXI ${ }^{2}$. E-mail: helena.marinho@ua.pt

\section{Resumo}

Esta pesquisa aborda o envolvimento em criação musical da autora e poetisa Fernanda de Castro (1900-1994), partindo do conceito de sociabilidade. Discute-se o enquadramento da sua produção artística ligada à música, em particular durante o período do Estado Novo em Portugal. A partir da identificação, caracterização e contextualização dessa produção, propõe-se uma análise da intersecção entre música, texto e género que lhe está subjacente.

\section{Palavras-chave}

Música portuguesa do século XX. Estado Novo em Portugal. Mulheres e música. Fernanda de Castro.

\section{1) Fernanda de Castro: uma autora no seu tempo}

Fernanda de Castro (1900-1994) é uma personalidade da cultura portuguesa do séc. XX raramente mencionada em pesquisa musicológica, já que se dedicou sobretudo ao campo da criação literária, como poetisa, dramaturga e autora de literatura infantil e de ficção. Não obstante a sua produção abrangente nestas áreas, é também patente a ausência de estudos sobre a sua obra literária ${ }^{3}$. Esteve ligada, por laços familiares e participação em actividades culturais, ao período do Estado Novo em Portugal, e é tentador associar esta limitada visibilidade actual a essa circunstância. Fernanda de Castro foi a esposa de António Ferro (1895-1956), director entre 1933 e 1949 do Secretariado da Propaganda Nacional (SPN; Secretariado Nacional de Informação, Cultura Popular e Turismo - SNI a partir de 1944), e que se assumiu, nessa qualidade, como um dos principais protagonistas da "política do espírito". Esta denominação,

\footnotetext{
${ }^{1}$ A autora agradece à Fundação António Quadros e à sua Presidente Mafalda Ferro a cedência de materiais ilustrativos, a autorização para a sua inclusão neste artigo e todas as informações disponibilizadas. Agradece também as sugestões dos colegas Maria do Rosário Pestana e Alfonso Benetti Junior.

Este artigo insere-se nas publicações do projecto "Euterpe Unveiled: Women in Portuguese musical creation and interpretation during the 20th and 21st centuries", financiado por Fundos FEDER através do Programa Operacional Competitividade e Internacionalização - COMPETE 2020 e por Fundos Nacionais através da FCT - Fundação para a Ciência e a Tecnologia no âmbito do projecto POCI-01-0145-FEDER016857 (Ref ${ }^{\mathrm{a}}$ FCT: PTDC/CPC-MMU/3559/2014).

2 A autora utiliza a norma designada de "antigo acordo ortográfico" em Portugal.

${ }^{3}$ Refira-se, entre os estudos que lhe são dedicados, Morão (2017) e Nunes (1996).
} 
inspirada num ensaio de Paul Valéry de idêntico título, foi escolhida por Ferro para designar a linha de acção no campo cultural do regime ditatorial de António de Oliveira Salazar, em especial nas décadas de 1930 e 1940 (RAMOS DO Ó, 1999). Enquanto director do SPN / SNI, Ferro promoveu uma estética das artes ao serviço do Estado e da sua propaganda (SANTOS, 2008) que viria a caracterizar a produção cultural dessa época, marcada pelo pendor conservador das temáticas e das linguagens, e pela complexa, e por vezes incómoda, articulação com o modernismo de algumas das perspectivas adoptadas (HENRIQUES, 1990).

Tanto Fernanda de Castro como António Ferro estabeleceram e cultivaram uma rede de contactos alargada que incluía personalidades nacionais e internacionais ligadas à cultura. $\mathrm{O}$ contacto desenvolvia-se a nível profissional, mas também pessoal, com frequentes convívios e encontros que estão referenciados em fontes diversas, nomeadamente nos materiais do arquivo da Fundação António Quadros ${ }^{4}$, em Rio Maior (Portugal), onde o acervo de vários membros da família está guardado. Esta rede de contactos e amizades é apresentada de forma mais intimista no diário intitulado Ao fim da memória, em dois volumes, que Fernanda de Castro publicou em 1986 e 1987 (CASTRO, 1988, 2005). Mesmo após o falecimento do marido, em 1956, Fernanda de Castro manteve a sua postura activa nas áreas da cultura e da intervenção social, como se descreve mais abaixo, e também o convívio e amizade com personalidades que colaboraram na génese das suas criações e eventos.

A ausência de abordagens a Fernanda de Castro na pesquisa académica sobre música poderá estar relacionada com a brevidade da sua acção enquanto criadora, e aos limites desta, que se resume à composição de melodias / canções no início da década de 1960. No entanto, a criação e a performance musical estiveram reiteradamente ligadas tanto às suas actividades de produção cultural como à sua obra literária: vários dos seus textos poéticos constituíram a base de canções com música de sua autoria e, sobretudo, de outros compositores, como Elvira de Freitas ou Afonso Correia Leite. Sendo embora limitada a sua produção como compositora, as intersecções operadas entre música e texto (nomeadamente poesia) na sua produção constituem um caso de particular relevância, pelas interacções fluídas entre as esferas privada e pública que lhes estiveram subjacentes, e pelo facto de se apoiarem, em grande parte, no contexto de redes de sociabilidade feminina.

\footnotetext{
${ }^{4}$ António Quadros (1923-1993) era filho de Fernanda de Castro e António Ferro. O site da Fundação António Quadros pode ser acedido em: http://www.fundacaoantonioquadros.pt/.
} 


\section{2) A sociabilidade como modelo}

A relevância das redes de sociabilidade para a produção musical tem sido referida em pesquisa musicológica para expor e discutir realidades de criação e programação aparentemente intersticiais, ou seja, que estão ausentes ou que não se enquadram nas grandes narrativas históricas relativas à música erudita ou a outras músicas, e que desafiam critérios estandardizados de classificação. O conceito das redes de sociabilidade pode ser visto como uma alternativa ao conceito de esfera pública / privada, proposto por Habermas, criticado pelas limitações do seu enfoque quanto à análise da participação das mulheres na esfera pública (LANDES, 1995). A articulação entre esferas, aliás, teve implicações específicas no contexto do Estado Novo em Portugal, que promoveu "sistemas de oposição entre o 'feminino' e o 'masculino"” (BRASÃO, 1999, p. 41), assim como a diferenciação dicotómica de áreas de acção, como salientou Irene Pimentel:

O regime salazarista mascarou, porém, a diferenciação de valores em função do género com uma aparente valorização social da função feminina e reservou às mulheres uma esfera própria de actuação, privada e pública, sem atribuir, contudo, ao espaço feminino um valor igual ao do masculino (PIMENTEL, 2011, p. 394).

A abordagem primeira ao conceito de sociabilidade foi proposta por Georg Simmel em 1911, que a definiu como:

a arte ou forma lúdica de associação, relacionada com o conteúdo e objectivos da associação, da mesma forma que a arte está relacionada com a realidade. Enquanto a interacção sociável é focada nas pessoas, [a sociabilidade] só pode ocorrer se os objectivos mais sérios do indivíduo estão ausentes, de forma a que seja uma interacção, não de personalidades completas, mas de personalidades simbólicas e iguais (SIMMEL, 1949, p. 254) .

Simmel reconheceu a natureza delicada do equilíbrio entre personalidades que sustenta o conceito, assim como o seu carácter abstracto, mas salientou o respectivo potencial na análise de determinados tipos de interacção social de cariz equilibrado e gratificante, ao longo da história. A abordagem de Simmel a questões de género decorrentes deste contexto, no entanto, demonstra marcas da época de escrita do seu artigo, ao focar-se em descrições da mulher como um ente coquette e sedutor. Não obstante, o seu conceito de sociabilidade, tal como desenvolvido em pesquisas posteriores de outros autores, demonstra permitir uma aplicação consequente em

\footnotetext{
${ }^{5}$ Todas as traduções deste artigo foram realizadas pela autora.
} 
estudos sobre tipos diversificados de redes, incluindo redes de sociabilidade de mulheres. É também necessário tomar em conta, quando nos debruçamos sobre o universo específico da produção musical de mulheres, que as redes têm funcionado como locus de acolhimento e validação de acções e comportamentos em contexto sancionado e protector (como destacado pelos estudos abaixo mencionados, relativos a música portuguesa). Esta perspectiva é também sugerida por pesquisas que abordam as práticas musicais como cultura "generificada", reconhecendo a complexidade das situações sociais e culturais que originam práticas diferenciadas de acordo com constructos sociais de género (MAGRINI, 2003). Mas o género, como Judith Butler salienta, não se estabelece como um locus identitário estável, antes como "uma identidade tenuemente constituída no tempo - uma identidade instituída através da repetição estilizada de actos" (BUTLER, 2013, p. 462). Daí decorre, ainda de acordo com Butler, mas numa perspectiva beauvoiriana, que "ser mulher é ter-se tornado mulher, compelido o corpo a tornar-se um signo cultural, materializar-se em obediência a uma possibilidade historicamente delimitada, e fazê-lo como um projecto sustentado e reiterado" (BUTLER, 2013, p. 464); ou seja, o género é essencialmente performativo, de acordo com esta autora.

Em pesquisa sobre música portuguesa, as redes de sociabilidade são um conceito aplicado por Teresa Cascudo (2017) na sua análise dos concertos e produção, enquanto compositora, da Condessa de Proença-a-Velha na transição para o séc. XX, ou por Manuel Deniz Silva (2014) nos seus estudos abordando os concertos promovidos pela cantora Ema Câmara Reis nas décadas de 1920 e $1930^{6}$. Tratam-se, em ambos os casos, de salões literários e/ou musicais, um contexto que Fernanda de Castro conhecia e frequentava, já que refere no seu diário o salão literário de Genoveva de Lima Mayer ${ }^{7}$ e o salão literário-musical de Elisa de Sousa Pedroso ${ }^{8}$, ambos em Lisboa, entre outros. Os estudos referidos partem de aplicações afins do enquadramento teórico da sociabilidade em autores como Jean-François Sirinelli (2003), que abordou a sociabilidade em grupos e redes de intelectuais, ou Myriam Chimènes (2004) e o seu estudo sobre os salões culturais franceses do início do séc. XX, que se constituíam como espaços

\footnotetext{
${ }^{6}$ Helena Lopes Braga (2013) também adopta este referencial teórico na sua dissertação sobre Francine Benoît, compositora e autora portuguesa de origem francesa.

${ }^{7}$ Pode-se consultar uma breve descrição desta personalidade, mais conhecida como Veva de Lima, e do seu salão, em Ramalho (2015).

${ }^{8}$ As publicações específicas sobre Elisa de Sousa Pedroso são escassas (ver CAPELA, 2011). Esta pianista foi fundadora, em 1934, de uma das sociedades de concertos mais activas durante o séc. XX em Portugal, o Círculo de Cultura Musical, com delegações em várias localidades portuguesas (ALMEIDA, 2008).
} 
intermediários entre os salões privados e as salas de concertos, mediando e legitimando práticas musicais situadas na fronteira entre as esferas privada e pública.

No caso de Fernanda de Castro, a documentação existente sustenta a pertinência do conceito de sociabilidade, numa perspectiva de performatividade de género (BUTLER, 2013), para a análise da sua actividade. Partiu-se também da hipótese de trabalho de, neste caso, o seu posicionamento em rede ter-se constituído como forma de viabilizar e sancionar uma participação pró-activa num contexto histórico e social adverso à promoção das mulheres no campo musical, como apontado em pesquisa relativa a esta área (MARINHO, 2017; RIBEIRO, 2016).

A pesquisa apresentada neste artigo teve como objectivo, portanto, identificar, caracterizar e contextualizar a produção e intervenção de Fernanda de Castro em música a partir do modelo da sociabilidade, analisando a intersecção performativa entre música, texto e género que lhes está subjacente. Não existindo publicações ou estudos sobre a actividade musical de Fernanda de Castro, os materiais e dados relativos a esta vertente foram obtidos através da consulta de publicações desta autora (nomeadamente o diário acima referido), de documentação constante dos acervos da Fundação António Quadros (manuscritos de música, guiões de obras teatrais com instruções de performance musical, textos e anotações referentes a conteúdos musicais, gravações, e correspondência), e através da realização de uma entrevista com a sua neta Mafalda Ferro ${ }^{9}$.

\section{3) Um percurso singular, entre a música, texto e género}

Os dados referentes a Fernanda de Castro, descritos mais abaixo, sustentaram a identificação preliminar de três áreas principais de acção, especificamente ligadas à criação musical:

1- a sua actividade como mecenas e promotora de projectos de base teatral que envolveram música criada especificamente para esses projectos por diversos compositores;

2- o seu papel como protectora de compositoras e intérpretes femininas, com quem, em alguns casos, manteve laços de grande proximidade profissional e pessoal;

\footnotetext{
${ }^{9}$ Entrevista realizada em Novembro de 2016; Mafalda Ferro é Presidente da Fundação António Quadros.
} 
3- a sua dedicação à composição de música vocal, durante um breve período, e a ligação, enquanto letrista, a compositores como Elvira de Freitas (1927-2015), Frederico de Freitas (1902-1980), ou a Condessa de Proença-a-Velha (1864-1944).

Constatou-se, logo na identificação e análise inicial destes dados, a recorrência de vários factores:

1- a importância que a música, na sua ligação com a criação literária, assume em praticamente todas as acções promovidas em contexto de redes de sociabilidade, e o facto de estas redes envolverem mulheres de forma sistemática e por vezes exclusiva;

2- não obstante a diversidade de perspectivas envolvidas (produção teatral, relações profissionais e pessoais com músicos, compositora e letrista), várias personalidades do seu círculo marcaram presença em todas estas vertentes, demonstrando a estabilidade das redes construídas;

3- a actividade literária desenvolvida por Fernanda de Castro assumiu-se como agente determinante e catalisador da criação musical, quer por parte de terceiros, quer por si própria, em circunstâncias diversas, também aqui demonstrando a persistência de um determinado modus operandi ao longo de várias décadas.

Daqui decorrem questões de investigação específicas, incidindo sobre a necessidade de caracterização dos contextos das redes constituídas à volta de Fernanda de Castro, mas também incidindo sobre as intersecções assumidas entre os seus interesses enquanto criadora de textos e de música. As três vertentes de acção referidas no início desta secção entrecruzam-se, de forma frequentemente indissociável, na cronologia do seu percurso pessoal e profissional, e a descrição que se segue tentará seguir precisamente essa cronologia, a partir da década de 1930.

\section{4) Redes em acção}

Dos projectos envolvendo música, destacam-se os eventos decorrentes da criação da Associação Nacional dos Parques Infantis por Fernanda de Castro, em 1933. Esta iniciativa, dissolvida apenas em $1979^{10}$, terá sido uma das que mais a envolveu e orgulhou, pelo que se deduz do seu diário (CASTRO, 2005). A Associação inaugurou já em 1932 o primeiro edifício, a que se seguiram outros, destinados a acolhimento de dia de crianças necessitadas de bairros de Lisboa. Para além da função pedagógica destes

\footnotetext{
${ }^{10}$ Data de dissolução oficial. A ligação de Fernanda de Castro à Associação Nacional dos Parques Infantis cessou efectivamente no início da década de 1970, quando passou a sua gestão à Santa Casa da Misericórdia (de acordo com informação do site da Fundação António Quadros).
} 
espaços, estava também prevista a alimentação e apoio médico das crianças. Nesta fase inicial de implementação, e de acordo com o seu diário, Fernanda de Castro trava conhecimento com colaboradoras que, em alguns casos, se tornarão amigas de longa data: Sarah Afonso, artista plástica, Heloísa Cid, escritora, Inês Guerreiro, pintora. Fernanda de Castro planeia então uma nova valência para um dos seus parques, que vem a designar de "Colmeia"; a implementação de:

\begin{abstract}
uma educação artística completa com a finalidade de ver os resultados de uma experiência deste género com crianças em "estado puro", ainda completamente libertas dos malefícios do mau gosto e de modas efémeras. Escolhemos por assim dizer ao acaso cem crianças de ambos os sexos, entre os cinco e os dez anos, e chamámos a este grupo "O Pássaro Azul” (CASTRO, 2005, p. 242).
\end{abstract}

Esta iniciativa revelou-se perene: consta do acervo da Fundação António Quadros um programa já da década de 1950 (Figura 1) em que se constata a importância que a música assumia nos eventos do grupo. Para além de apresentações de repertório canónico de música erudita, de compositores como Beethoven ou Chopin e também de autores portugueses como Óscar da Silva ou Nina Marques Pereira, o evento incluía declamação de poesia e a apresentação de uma peça teatral de Fernanda de Castro. É também de notar o relevo dado à componente coral, aliás uma das áreas de performance musical privilegiadas no período do Estado Novo, assumindo contornos de intervenção política e social herdados do movimento orfeónico português ${ }^{11}$ de inícios do século XX (ARTIAGA, 1999; PESTANA, 2010).

\footnotetext{
${ }^{11}$ Maria do Rosário Pestana caracteriza da seguinte forma este movimento: "o orfeão foi um modelo ou programa transnacional de fazer música e expressar ideias [...] que simultaneamente inspirou um largo projecto nacionalista e conluiou etnógrafos e folcloristas na institucionalização de orfeões e na selecção, registo e performance de um suposto lastro de nacionalidade" (PESTANA, 2014, p. 8).
} 


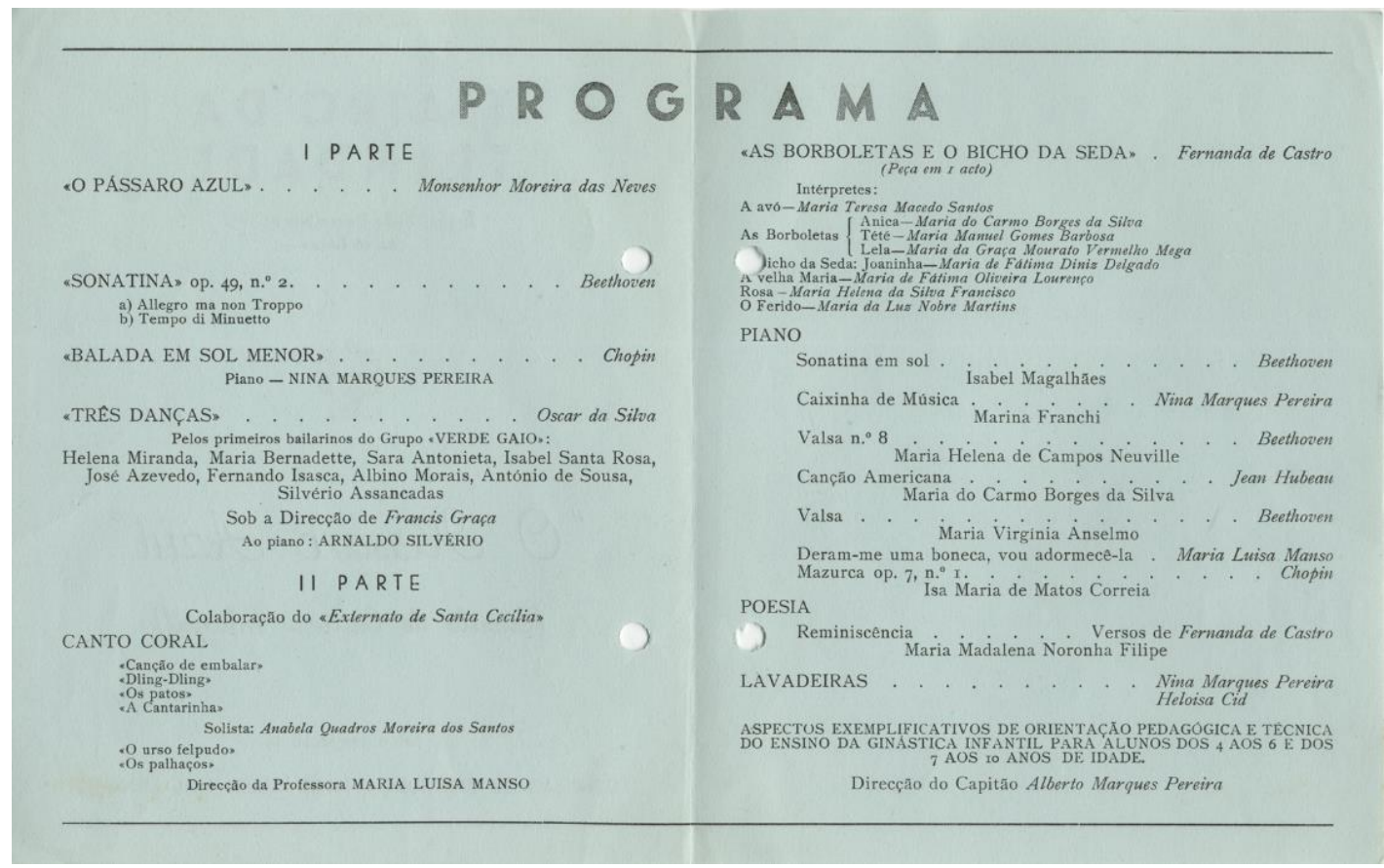

Figura 1: Programa de apresentação de "O Pássaro Azul" (Círculo de Cultura Infantil) no Teatro da Trindade, em Lisboa, a 23/12/1957. Fonte: arquivo da Fundação António Quadros.

O "Pássaro Azul” integrava um ambicioso programa de educação pela arte, com uma componente de intervenção social. Em programas e registos dos eventos associados, são referidos, para além dos nomes já mencionados, outros colaboradores: do teatro Eunice Muñoz e Carmen Dolores, da declamação Germana Tânger, da dança Anna Mascolo e Águeda Sena, da música Júlia de Almendra, Arminda Correia e Nina Marques Pereira. Integrava, pois, esta equipa um número significativo de mulheres que já marcavam ou vieram a marcar as artes e cultura portuguesas do séc. XX. É significativa também esta ligação de um grupo de criadoras a um contexto de âmbito educativo: a promoção e validação da ligação da mulher ao campo da educação foi precisamente uma das marcas da política do Estado Novo (PIMENTEL, 2011). No que diz respeito à música, e de acordo com informação dos diários e dos materiais de arquivo, Nina Marques Pereira terá sido a principal agente de dinamização no projecto dos Parques. As únicas partituras localizadas até à data desta pianista e compositora - a peça infantil O Urso Peludo, e o bailado As meninas exemplares, ambas para piano foram compostas precisamente para iniciativas dos Parques ${ }^{12}$.

Esta não era apenas uma equipa de trabalho, era também uma equipa de afectos, marcada pelos laços de amizade existentes ou consolidados nestas actividades. Aliás, o

\footnotetext{
${ }^{12}$ Partituras manuscritas constantes do acervo da Fundação António Quadros. As pesquisas realizadas em arquivos públicos e privados no sentido de encontrar mais obras desta compositora não tiveram ainda sucesso.
} 
seu núcleo central, nomeadamente com Nina Marques Pereira, Inês Guerreiro e Heloísa Cid, manteve-se coeso mesmo após o fim do grupo, por falha no financiamento, no início da década de 1960. O projecto dos Parques constituiu-se assim como um exemplo de produção e intervenção multidisciplinar liderado por Fernanda de Castro, envolvendo exclusivamente mulheres na equipa criativa, com uma forte componente musical.

\section{5) As canções}

O falecimento de António Ferro em 1956 e as alterações políticas a partir da década de 1950 não afectaram o interesse de Fernanda de Castro pelo desenvolvimento de projectos integrando diversas vertentes artísticas, e a associação e amizade com personalidades ligadas às artes mantiveram-se. O contexto político, social e económico estava em mutação: a "agonia do salazarismo" (ROSAS, 1998) era patente na oposição crescente, na desagregação interna das forças políticas, e na complicada gestão das designadas “províncias ultramarinas” em África e do conflito armado daí decorrente.

Ao núcleo de amigas mais próximas de Fernanda de Castro vieram juntar-se, na década de 1960, Edith Arvelos, jornalista e pianista moçambicana que veio para Lisboa para residir com Fernanda de Castro, tornando-se sua secretária e colaboradora, os autores José Carlos Ary dos Santos e Natália Correia (CARDOSO, 2011) e, presumivelmente já na década de 1970, Elvira de Freitas, filha do compositor Frederico de Freitas ${ }^{13}$.

Estas ligações estiveram na base do envolvimento ainda mais próximo de Fernanda de Castro com a música, a partir da década de 1960. No seu diário, descreve as circunstâncias:

Lembrámo-nos então daqueles joguinhos de sala em que a Natália Correia e o Ary eram mestres e começámos o jogo das uvas, o jogo dos provérbios [...]. Propus: vamos lá a ver qual de nós é capaz de inventar um fado [...] fiz o meu fado que ganhou o desafio e que prevaleceu. Todos os outros caíram no esquecimento, mas o meu, com versos alinhados na mesma altura, ainda seria digno (ou será ilusão?) dum L. P. qualquer. [...] tendo-lhe tomado o gosto, 'compus' mais tarde umas 50 musiquinhas de todos os géneros: fados, canções, marchas populares, baladas de Coimbra, etc., etc., etc. Eu não sabia nem sei uma única nota de música e a coisa passava-se assim: fazia o poema, aplicava-lhe a música, trauteava, cantarolava e a desgraçada da Edith, que tem um ouvido musical perfeito, ia escrevendo assim:

\footnotetext{
${ }^{13}$ Há referências à amizade de longa data entre as famílias de Fernanda de Castro e do compositor Frederico de Freitas em várias fontes, nomeadamente na documentação constante do espólio deste compositor na Biblioteca da Universidade de Aveiro. Também nesta Biblioteca se encontra o espólio da filha, e Fernanda de Castro é referida nas suas memórias, ainda inéditas. Existem descrições de contactos entre ambas desde a infância de Elvira, contactos que se estreitaram com a entrada desta na idade adulta.
} 
dó, mi bemol, sol sustenido, o que fosse, isto sem utilizar a pauta, e portanto as notas eram palavras, num caderno de 35 linhas, uma vez que ela só tocava piano de ouvido [...] a maior parte destas cantiguinhas eram inventadas nas viagens de automóvel, sobretudo para o Algarve (CASTRO, 2005, p. 201-202).

Encontram-se na Fundação António Quadros várias anotações de melodias efectuadas por Edith Arvelos, com os nomes das notas registados por extenso, confirmando que a copista não lia ou escrevia música. Segundo informação de Mafalda Ferro, seriam outras amigas de Fernanda de Castro, como Nina Marques Pereira ou Elvira de Freitas, que ajudariam na transcrição destas canções para notação musical (entrevista a Mafalda Ferro). Fernanda de Castro não terá encarado estas criações como mera diversão, já que na Fundação António Quadros se encontram registos formais das suas melodias na Sociedade de Escritores e Compositores Teatrais Portugueses ${ }^{14}$. Estas fichas de registo, com carimbos de recepção na Sociedade, são relativas a 16 melodias, quatro sem data, e as restantes de 1963 e 1964. Os dados assinalados no campo "género" destas fichas confirmam a predilecção de Fernanda de Castro pela canção, fado e marcha. Em praticamente todos os registos foi autora também da letra, como vemos no exemplo da Figura 2, o fado "Um grande amor", com os dados da melodia na frente da ficha e, no verso, o seu registo em pauta; a letra do fado consta de uma folha dactilografada anexa.

\footnotetext{
${ }^{14}$ Instituição que veio a originar a actual Sociedade Portuguesa de Autores.
} 


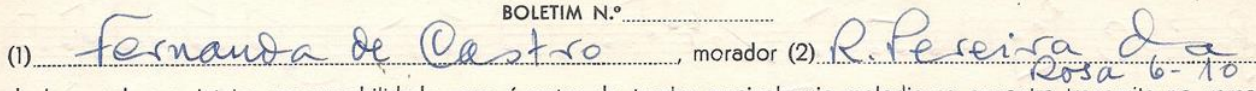
declara, sob sua inteira responsabilidade, que é autor do trecho musical cuja melodia se enconira transcrita no verso.

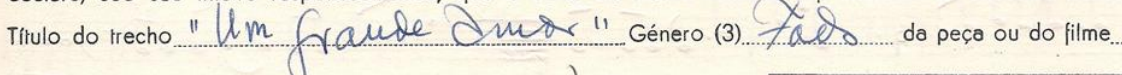

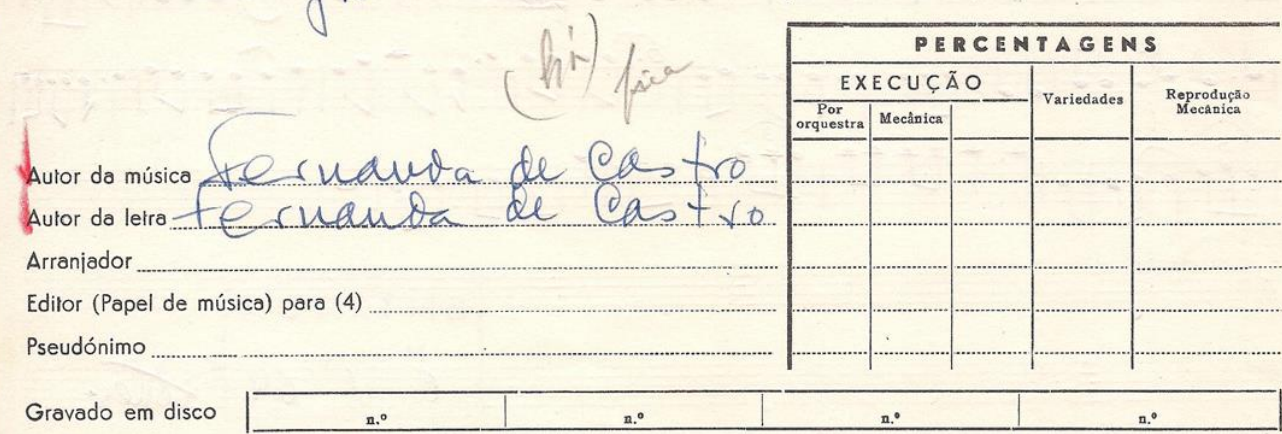

Observaçōes

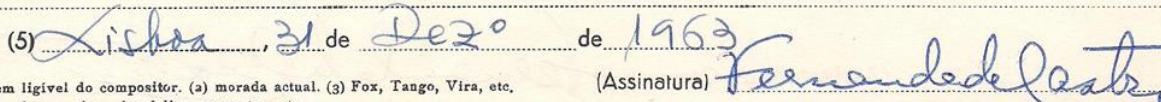

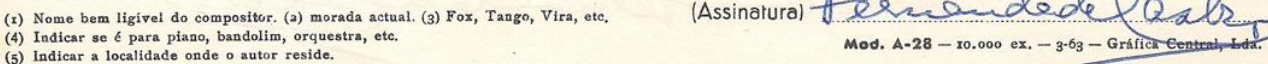

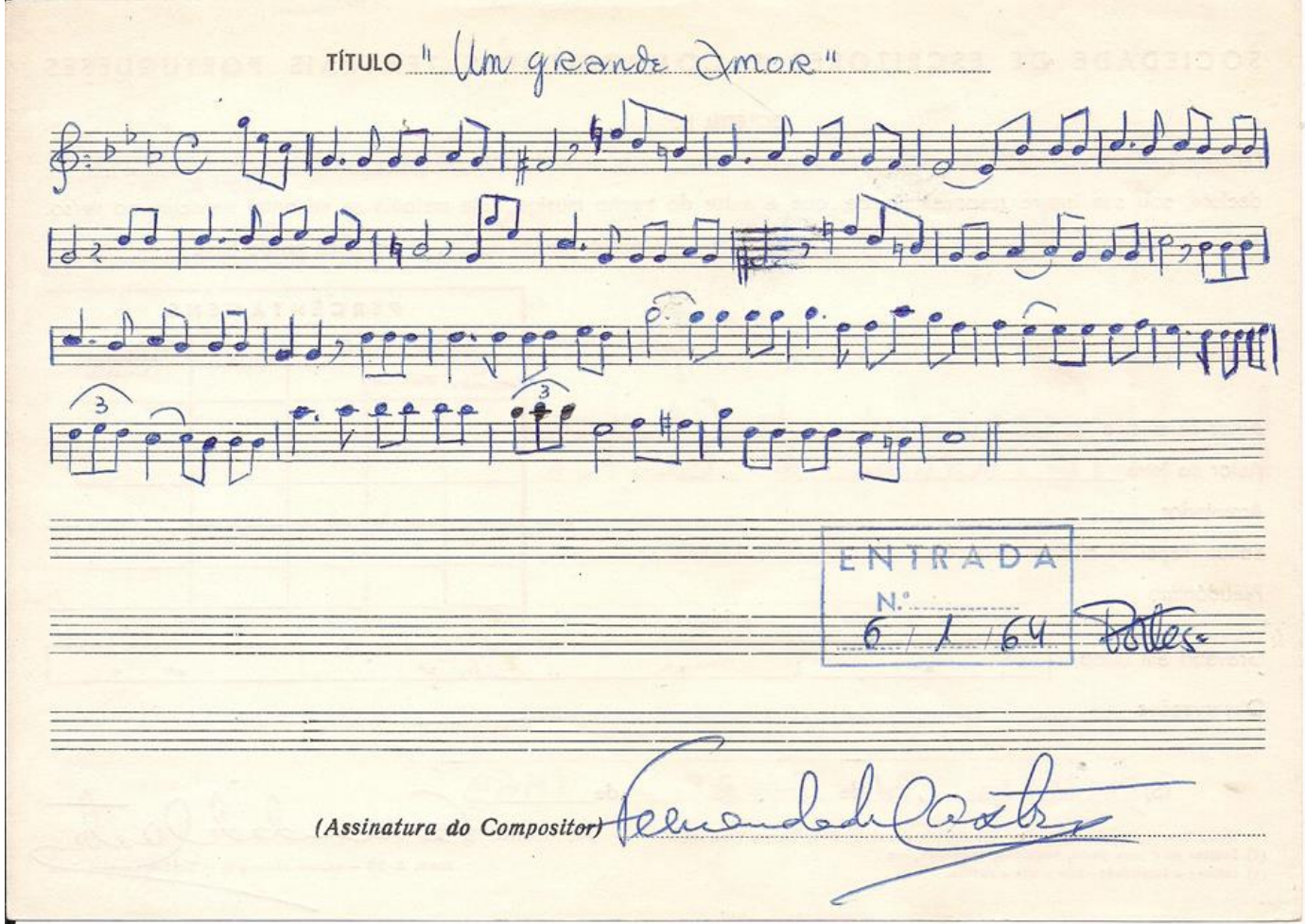

Figura 2: Registo (frente e verso) na Sociedade de Escritores e Compositores Teatrais Portugueses do fado "Um grande amor", de Fernanda de Castro. Fonte: arquivo da Fundação António Quadros.

Entre os temas que Fernanda de Castro destaca no diário estão o seu fado "O Domingo do mundo é Primavera", que terá sido interpretado com alguma frequência pelo fadista António Mourão, e também menciona outras melodias cantadas por Guida Homem de Sousa. Terá também sido gravado um disco integralmente constituído por 
canções para crianças com letras e música de Fernanda de Castro, que ainda não se conseguiu localizar. O interesse pelo registo das melodias que cantava foi de curta duração. Refere no seu diário, sem detalhes que nos permitam perceber este abandono, e sem referência a data específica (mas em contexto que sugere situar-se ainda na década de 1960): "Esta onda passou e eu voltei ao silêncio, deixando para sempre em paz as escalas cromáticas de todos os continentes" (CASTRO, 2005, p. 203).

Mas o seu interesse pela música manteve-se, predominantemente como autora de letras. Embora neste campo tenha ficado mais associada com o contexto do fado e canção ligeira, há pelo menos um registo de utilização de texto seu ${ }^{15}$ numa obra musical erudita: Nocturno - Soneto para voz e piano, publicada em edição de autor pela Condessa de Proença-a-Velha em 1934. Subsequentemente, surge associada, enquanto letrista, a outros contextos: em colaboração com Frederico de Freitas, por exemplo, como autora de letra de canções do filme de Leitão de Barros As Pupilas do Senhor Reitor (1935), ou na criação de fados com Elvira de Freitas, como descrito mais à frente. A sua preferência manifesta pelo fado enquanto autora de melodias acaba por se prolongar também nesta ligação ao fado enquanto letrista. A recepção do fado, no entanto, não era consensual junto de alguns músicos próximos de Fernanda de Castro. Em 1934, Frederico de Freitas afirmava, numa entrevista a um jornal do Rio de Janeiro:

O fado é uma musica inferior, uma musica de bairro, sem expressão de arte que não pode, que não é a musica portugueza. É uma melodia triste, que só lembra infelicidades, que canta somente a desdita. A alma portugueza não é absolutamente a do fado como querem fazer crer (Diário da Noite, 18/7/1934).

Esta declaração, por parte do autor de ensaios sobre o assunto, e de alguns dos fados mais conhecidos do repertório (como é o caso dos fados compostos para o primeiro filme sonoro português, A Severa, de 1931, ou dos fados de Amália Rodrigues no filme Fado, História d'uma Cantadeira, de 1947), suscita perplexidade. A contradição implícita traduz o incómodo que o fado, enquanto canção urbana associada a grupos sociais marginalizados, causava no campo cultural, e reflecte a gestão difícil da sua aceitação ou rejeição por parte do regime do Estado Novo (NERY, 2004). Este incómodo aparentemente não afectou Fernanda de Castro: está patente nas suas descrições do diário uma naturalidade e entrega evidentes na forma como se relacionava com as suas áreas de interesse.

\footnotetext{
${ }^{15}$ Do livro Cidade em Flor, de 1924.
} 
Um dos projectos que Fernanda de Castro abraçou a partir da década de 1960 foi o Teatro de Câmara António Ferro, contando com Edith Arvelos para a produção musical dos eventos. As primeiras apresentações do Teatro de Câmara António Ferro tiveram lugar na esfera privada da casa de Fernanda de Castro (CASTRO, 2005). O primeiro projecto envolveu Ary dos Santos, Germana Tânger, Alexandre Ribeirinho, Heloísa Cid, e era baseado num longo poema de Fernanda de Castro, "Rua Velha", escrito em 1962. Vários guiões / roteiros deste projecto estão guardados na Fundação António Quadros; embora não incluam música, a pesquisa de arquivo permitiu identificar várias partituras ligadas a esta performance, cruzando a descrição dos números musicais mencionados no guião e alguns manuscritos musicais dispersos no acervo. No entanto, não foi possível ainda atribuir autoria a estes manuscritos, que poderão ser cópias de material pré-existente ${ }^{16}$.

Verifica-se também, nesta fase fortemente focada na composição e escrita para canções, a importância das redes de sociabilidade, que continuaram a privilegiar a participação de mulheres. O enfoque no ensino, verificado nas actividades dos parques, é transferido para a criação musical como finalidade em si própria, e Fernanda de Castro, com o apoio das amigas, concretiza a fusão entre criação literária e composição nas suas canções, e integra música em projectos de cariz teatral.

\section{6) Os últimos projectos}

Há um aparente interregno referente à música, tanto nos diários, como na documentação, entre meados da década de 1960 e meados da década de 1970. Mas Fernanda de Castro continua nesta fase a organizar eventos ainda pouco estudados: o $1^{\circ}$ e $2^{\circ}$ festivais do Algarve, respectivamente em 1964 e 1965, de novo com as colaboradoras principais desta fase, Inês Guerreiro, Nina Marques Pereira e Edith Arvelos (Figura 3).

\footnotetext{
16 "Rua Velha" foi o único caso de apresentação em que se conseguiu estabelecer uma ligação clara com a sua componente musical a partir dos materiais de arquivo, mas presume-se que outras apresentações poderão ter incluído idêntica ligação a música.
} 


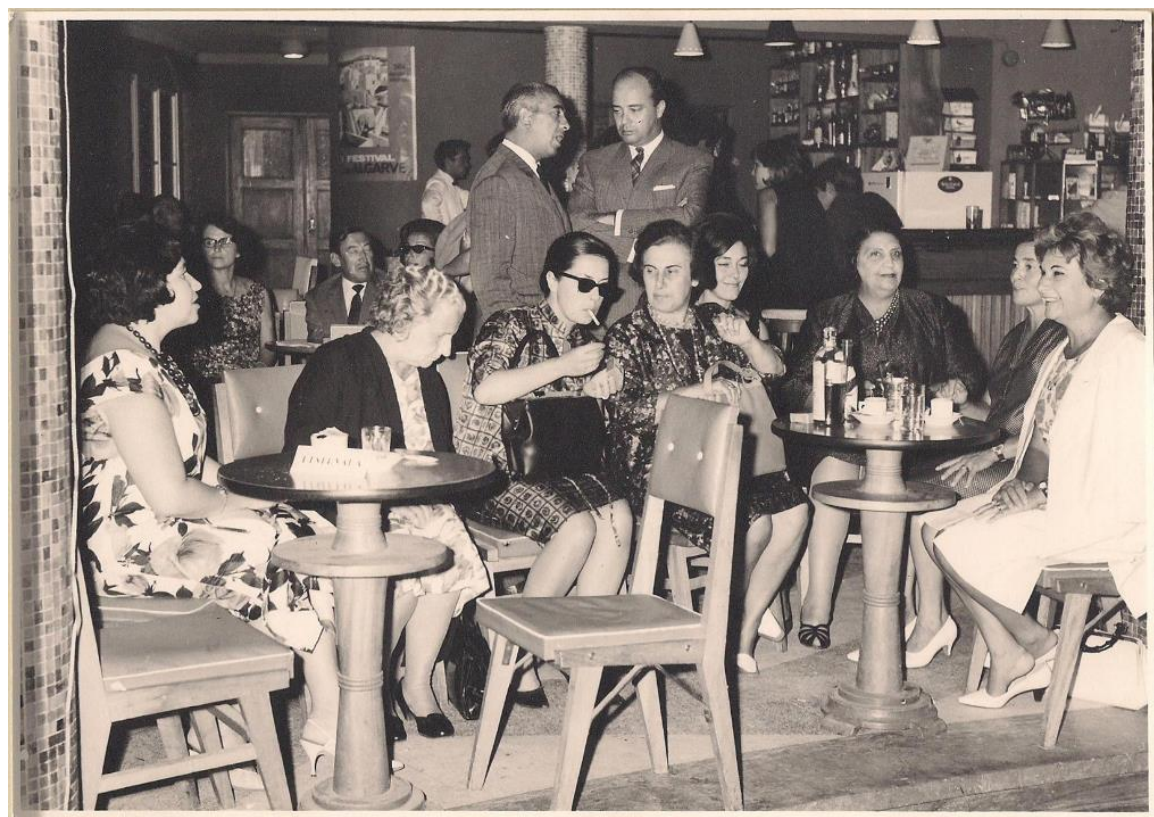

Figura 3: foto da altura do $1^{\circ}$ Festival do Algarve: Fernanda de Castro ( $3^{\mathrm{a}}$ a partir da direita) com as amigas pianistas Edith Arvelos ( $3^{\mathrm{a}}$ a partir da esquerda) e Nina Marques Pereira (à direita de Fernanda de Castro). Fonte: arquivo da Fundação António Quadros.

Mantém também os encontros com artistas amigos, cultivando o hábito de os transformar em momentos de desenvolvimento de projectos e de trabalho em equipa (entrevista com Mafalda Ferro). Um dossier existente na Fundação António Quadros reúne várias dezenas de letras de canções, algumas com indicação dos artistas a quem se destinavam, ou que as terão cantado, como Ada de Castro, António Mourão, Alice Maria, Guida Homem de Sousa, ou Miguel Barata-Feyo. Pelo estilo dos textos e pela identificação dos cantores, resulta evidente que se destinavam a música de fado. É possível que vários destes textos tenham sido musicados por Elvira de Freitas, embora também haja alguns para os quais Fernanda de Castro compôs as melodias. Esse cruzamento de dados depende, para a sua conclusão, de futuros estudos da obra de Elvira de Freitas, ainda por explorar, mas a data coincide com um período em que houve troca de correspondência frequente entre ambas. Curiosamente, correspondiam-se em francês, e é marcante o tom intimista de alguns textos. Fernanda de Castro era a confidente que consolava Elvira de Freitas, numa fase abertamente difícil da sua vida. Em carta datada de Setembro de 1979, Fernanda escreve:

Um aveu: si vous avez besoin de ma force (?), j'aurais besoin de votre faiblesse (?). Notre rencontre, vous le savez bien, n'est pas une 
rencontre de hasard: nous nous sommes rencontrées parce que nous devions nous rencontrer ${ }^{17}$.

Mas também se refere à música de Elvira de Freitas nessa mesma missiva: "Je pense beaucoup à vos chansons, qui sont douces, belles, caressantes. Envoyez-moi tous les monstres que vous voudrez"18. Os "monstros" que Fernanda de Castro menciona é um termo jocoso usado pelas duas para se referir às canções de Elvira de Freitas. A colaboração foi anterior a esta troca de correspondência, e esteve na génese de um LP, editado em 1974, cantado por Ada de Castro, e pensado como um projecto colaborativo das duas amigas (Fernanda de Castro como autora dos textos, e Elvira de Freitas como compositora). Destaca-se o tema que deu o título ao trabalho, "Alguém mandou-me violetas", e que constitui um exemplo da escrita que Fernanda de Castro produzia com vista à criação de canções. Infelizmente, não chegaram até nós descrições do tipo de trabalho colaborativo que as autoras poderão ter adoptado, o que teria permitido uma abordagem mais aprofundada na perspectiva da melopoética (KRAMER, 2017; SCHER, 2004). Mas existe uma partitura autógrafa de Elvira de Freitas ${ }^{19}$, relativa apenas ao refrão da canção, que nesse documento ficou redigido da seguinte forma:

Violetas, violetas,

Alguém mandou-me violetas

E as longas horas d'outono

De roxas, ficaram pretas

Violetas, violetas,

Gotas de tédio e abandono

De tristeza sem remédio

E nem sequer tenho sono.

A partitura, com numerosas rasuras e ligações entre palavras, sugere que o trabalho de colaboração poderá ter sido complexo. A julgar pelas correcções registadas, é possível que a elaboração dos textos tenha precedido a composição da melodia. A forma como o poema foi estruturado e a escolha da temática sugerem que Fernanda de Castro tinha conhecimento dos modelos textuais que poderiam, ou não, funcionar no contexto da criação de fado (mesmo que a experiência de Elvira de Freitas no campo da escrita possa ter influenciado a forma final do texto).

\footnotetext{
${ }^{17}$ Tradução: "Uma confissão: se precisas da minha força (?), eu preciso da tua fraqueza (?). O nosso encontro, como sabes, não foi obra do acaso: encontramo-nos porque nos devíamos encontrar"; carta do arquivo da Fundação António Quadros.

${ }^{18}$ Tradução: "Penso muito nas tuas canções, que são doces, belas, acariciantes. Envia-me todos os monstros que quiseres"; carta do arquivo da Fundação António Quadros.

${ }^{19}$ Manuscrito autógrafo do espólio de Elvira de Freitas na Biblioteca da Universidade de Aveiro. A gravação deste fado pode ser ouvida em https://www.youtube.com/watch?v=c5u9-Acf_uw.
} 
Por volta de 1981, a saúde de Fernanda de Castro deteriorou-se e um AVC deixou-a acamada. Passou a receber os seus amigos no quarto, mas sem diminuir totalmente o seu nível de actividade, graças ao apoio de Edith Arvelos. Aliás, uma gravação constante do acervo da Fundação António Quadros, efectuada por Daniel Gouveia em data incerta, mas provavelmente na fase de preparação de um disco de marchas de Lisboa cantadas por Miguel Barata-Feyo, constitui uma ilustração da forma como decorriam estas tertúlias em casa de Fernanda de Castro. Na gravação ouve-se Fernanda de Castro a declamar e a cantar, com o entusiasmo que sempre incutiu a esta actividade, com o acompanhamento de Edith Arvelos ao piano, e intervenções de Miguel Barata-Feyo e Daniel Gouveia.

\section{7) Intersecções}

Jennifer Post (1994), na sua análise das esferas pública e privada nas tradições performativas, defende que não existe uma oposição binária simples no enquadramento social que as separa, ou que separa as mulheres e as esferas a que supostamente estarão ligadas, sendo mais correcto falar de um continuum. Esta visão, como anteriormente referido, também se reflecte no conceito de performatividade de género, que defende que este é construído pela história e pela reiteração e estilização de actos performativos (uma abordagem também partilhada nas áreas da antropologia e estudos em performance por, respectivamente, Victor Turner e Richard Schechner).

Fernanda de Castro é um exemplo pertinente, no contexto da cultura portuguesa e também da criação e prática musical, desta fluidez e continuidade de acção performativa entre esferas, inserida numa realidade social e política construída sobre modelos cisnormativos na atribuição de papéis de género. De acordo com os dados recolhidos, operou predominantemente em áreas sancionadas e incentivadas pelas ideologias do Estado Novo no que diz respeito à participação das mulheres, nomeadamente em contexto educativo, mas, com o apoio das redes que integrou, conseguiu o alargamento do âmbito e visibilidade da sua produção.

Este alargamento de âmbito, apesar das limitações impostas às mulheres na época, esteve ligado à variedade dos contextos vivenciados por Fernanda de Castro, a que não foi alheio o facto de pertencer a uma elite cultural e social. Conheceu os salões intelectuais da $1^{\text {a }}$ República, a "política do espírito" do Estado Novo (por contacto indirecto com a acção profissional do marido e através das suas próprias iniciativas), a boémia de Lisboa na transição para a década de 1970 (com amigos como Natália 
Correia e Ary dos Santos), e as alterações culturais e sociais decorrentes do regresso à democracia em 1974. Não obstante esta diversidade, as actividades acima discutidas revelam processos de continuidade na criação e na produção ligada ao campo cultural.

Um desses elementos de continuidade reside na constituição de redes de sociabilidade como modelo de acolhimento, apoio criativo e validação. Estas redes foram constituídas, num período inicial, apenas por mulheres, mantendo essa preferência também em períodos posteriores. $\mathrm{O}$ apoio dessas mulheres permitiu, por exemplo, que Fernanda de Castro conseguisse registar as suas composições, mas também produzir eventos e iniciativas multidisciplinares, em que se combinava literatura, textos dramatúrgicos, artes plásticas, dança, música. Mas Fernanda de Castro não foi a única a beneficiar do apoio destas redes: houve efectiva partilha de conhecimentos e produção, e as criadoras envolvidas também aí acharam um lugar de expressão e validação da sua acção, nesse encontro de iguais que Simmel descreveu no seu artigo sobre sociabilidade.

Não foi objecto deste estudo aprofundar a análise da produção literária de Fernanda de Castro. É ainda assim inevitável, relativamente à intersecção de género, música e texto, constatar a motivação da palavra escrita em todas as suas realizações no campo da música, e também verificar como o trabalho em rede, nomeadamente com mulheres, associado a múltiplas vertentes de criação, se constituiu como a base dessa intersecção. Permitiu também, através da sua participação enquanto poetisa e autora, a criação de um locus de partilha socialmente validado e aparentemente imune à discriminação de género legal e ideologicamente instaurada durante o Estado Novo. As alterações políticas e sociais no período imediatamente anterior e também posterior à instauração da democracia (em 1974) foram graduais, mas as actividades de Fernanda de Castro, ligando as suas criações textuais e música, continuaram a evidenciar uma continuada inserção em redes de sociabilidade em que as mulheres se destacavam. De resto, o diário de Fernanda de Castro demonstra a sua consistência, em final de vida, relativamente aos valores e visões que a tinham caracterizado ao longo da vida, não assumindo aí conflitos ou críticas marcantes com a sua condição de mulher em função das visões de época.

As motivações para esta consistência na continuidade e na intersecção multidisciplinar poderão ter raízes na sua própria personalidade criativa e também na reiteração performativa que, como apontado acima, se constitui como marca identitária de género. É possível que Fernanda de Castro se tenha assumido, durante o Estado 
Novo, como uma descendente das redes de sociabilidade que frequentou na sua juventude e início da idade adulta, ligadas ao período da $1^{\text {a }}$ República, e que tal opção se tenha vindo a reflectir numa postura cultural sistematicamente interventiva $\mathrm{e}$ multidisciplinar, incluindo a incursão relativamente tardia e breve pela área da criação musical.

A intersecção entre artes que cultivou, com ênfase particular na palavra e na música, constituiu-se assim como um acto de performatividade de género (BUTLER, 2013), que lhe permitiu expressar-se apesar das limitações impostas às mulheres do seu tempo. Nunca rejeitando, nos seus escritos, a orientação "doméstica" (POST, 1994) que fundamentava então a separação dicotómica de funções e tarefas entre homens e mulheres, Fernanda de Castro encontrou e construiu um percurso criativo no cruzamento e intersecção das artes da palavra e da música. Assim, no esteio dos salões culturais da sua juventude, incorporou uma visão multidisciplinar e performativa nas temáticas, discursos e estilos das suas produções, mas que projectou para além do mundo dos salões: da esfera do seu lar a projectos de intervenção social de grande exposição pública, passando pela composição e criação com o apoio das redes que formou e que a rodearam, e que também evidenciaram uma marca histórica e socialmente reiterada de género. Compete à pesquisa de hoje em dia expor estas realidades fecundas e influentes, mas apagadas e ignoradas em prol de discursos e abordagens centradas na criação realizada por homens.

\section{Referências}

ALMEIDA, Ana Cristina. Memórias no feminino: o Círculo de Cultura Musical do Porto (1937-2007). 2008. 249f. Dissertação (Mestrado em Música) - Universidade de Aveiro, Aveiro, 2008.

ARTIAGA, Maria José. A disciplina de canto coral no período do Estado Novo: contributo para a história do ensino da educação musical em Portugal. 1999. 172f. Dissertação (Mestrado em Ciências Musicais) - Universidade Nova de Lisboa, Lisboa, 1999.

BRAGA, Helena Lopes. De Francine Benoît e algumas das suas redes de sociabilidade: invisibilidades, género e sexualidade entre 1940 e 1960. 2013. 154f. Dissertação (Mestrado em Ciências Musicais) - Universidade Nova de Lisboa, Lisboa, 2013.

BRASÃO, Inês Paulo. Dons e disciplinas do corpo feminino: os discursos sobre o corpo na história do Estado Novo. Cruz Quebrada: Organizações Não Governamentais do Conselho Consultivo da Comissão para a Igualdade e para os Direitos das Mulheres, 
1999.

BUTLER, Judith. Performative acts and gender constitution: an essay in phenomenology and feminist theory. In: MCCANN, Carole R. \& KIM, Seung-kyung. (eds.). Feminist theory reader: local and global perspectives. New York: Routledge, 2013. p. 462-473.

CAPELA, Maria da Conceição Barros. A música e ASC na $\mathbf{1}^{\mathrm{a}}$ metade do século XX: um estudo efetuado a partir de Elisa Baptista de Sousa Pedroso. 2011. 126 f. Mestrado (2. ${ }^{\circ}$ Ciclo em Ciências da Educação e Especialização em Animação Sociocultural) Universidade de Trás-os Montes e Alto Douro, Chaves, 2011.

CARDOSO, Manuel. José Carlos Ary dos Santos - as outras faces de um poeta. Tellus: Revista de Cultura Transmontana e Duriense, Vila Real, v. 54, p. 29-47, 2011.

CASCUDO, Teresa. The musical salon of the Countess of Proença-a-Velha in Lisbon: a case of patronage and activism at the turn of the twentieth century. NineteenthCentury Music Review, Cambridge, v. 14, nº 2, p. 195-210, 2017.

CASTRO, Fernanda de. Ao fim da memória II (1939-1987). Lisboa: Verbo, 1988.

CASTRO, Fernanda de. Ao fim da memória I (1906-1939). Lisboa: Círculo de Leitores, 2005.

CHIMÈNES, Myriam. Mécènes et musiciens: du salon au concert à Paris sous la IIIe République. Paris: Fayard, 2004.

DENIZ SILVA, Manuel. O Orpheon Portuense no contexto das sociabilidades musicais eruditas em Portugal: notas para um roteiro de pesquisa. In: ARAÚJO, Henrique Luís Gomes de. (ed.). A Sociedade Orpheon Portuense (1881-2008): tradição e inovação. Porto: Universidade Católica Editora, 2014. p. 102-111.

HENRIQUES, Raquel Pereira. António Ferro: estudo e antologia. Lisboa: Alfa, 1990.

KRAMER, Lawrence. Song acts: writings on words and music. Leiden: Brill/Rodopi, 2017.

LANDES, Joan B. The public and the private sphere: a feminist reconsideration. In: MEEHAN, Johanna. (ed.). Feminists read Habermas: gendering the subject of discourse. New York: Routledge, 1995. p. 91-116.

MAGRINI, Tullia (ed.). Music and gender: perspectives from the Mediterranean. Chicago: University of Chicago Press, 2003.

MARINHO, Helena. Vozes femininas na colecção de correspondência do compositor Frederico de Freitas. In: BESSE, Maria Graciete et al. (eds.). Exiliance au féminin dans le monde lusophone (XXe-XXIe siècles). Paris: Editions Hispaniques, 2017. p. 301-310.

MORÃO, Paula. Fernanda de Castro, Ao Fim da Memória: memoirs of a Portuguese 
century. In: BLANCO, Maria-José \& WILLIAMS, Claire. (eds.). Feminine singular: women growing up through life-writing in the Luso-Hispanic world. Oxford: Peter Lang, 2017. p. 129-148.

NERY, Rui Vieira. Para uma história do fado. Lisboa: Edições Público, 2004.

NUNES, Virgínia de Carvalho. O sol de frente na poesia de Fernanda de Castro. Revista Universidade de Aveiro - Letras, Aveiro, v. 13, p. 35-44, 1996.

PESTANA, Maria do Rosário. Um ritual de regeneração e transcendência: o canto orfeónico nas primeiras décadas do século XX. E-Cadernos CES, Coimbra, nº 8, p. 93$107,2010$.

PESTANA, Maria do Rosário. Introdução - cantar em coro em Portugal (1880-2014): práticas, contextos, ideologias. In: PESTANA, Maria do Rosário. (ed.). Vozes ao alto: cantar em coro em Portugal (1880-2014). Lisboa: mpmp, 2014. p. 5-41.

PIMENTEL, Irene Flunser. A cada um o seu lugar: a política feminina do Estado Novo. Lisboa: Círculo de Leitores, 2011.

POST, Jennifer C. Erasing the boundaries between public and private in women's performance traditions. In: COOK, Susan C. \& TSOU, Judy. (eds.). Cecilia reclaimed: feminist perspectives on gender and music. Urbana: University of Illinois Press, 1994. p. 35-51.

RAMALHO, Alfredo Magalhães. Associação Casa Veva de Lima. Revista Gaudium Sciendi, Lisboa, v. 8, p. 116-121, 2015.

RAMOS DO Ó, Jorge. Os anos de Ferro. O dispositivo cultural durante a «Política do Espírito» 1933-1949: ideologia, instituições, agentes e práticas. Lisboa: Editorial Estampa, 1999.

RIBEIRO, Paula Gomes. Da diversidade como ameaça: "le péril rose" ou a música na construção social de papéis de género. In: JESUS, Isabel Henriques de et al. (eds.). Falar de mulheres: dez anos depois. V. N. Famalicão: Edições Húmus, 2016. p. 35-45.

ROSAS, Fernando. O Estado Novo (1926-1974). Lisboa: Editorial Estampa, 1998.

SANTOS, Graça dos. Política do espírito: o bom gosto obrigatório para embelezar a realidade. Media \& Jornalismo, Coimbra, v. 12, nº 12, p. 59-72, 2008.

SCHER, Steven Paul. Literature and music. In: BERNHART, Walter \& WOLF, Werner. (eds.). Word and music studies: essays on literature and music (1967 -2004) by Steven Paul Scher. Amsterdam: Rodopi, 2004. p. 173-201.

SIMMEL, Georg. The sociology of sociability. American Journal of Sociology, Chicago, v. 55, no 3, p. 254-261, 1949.

SIRINELLI, Jean-François. Os intelectuais. In: RÉMOND, René. (ed.). Por uma história política. Rio de Janeiro: Editora FGV, 2003. p. 231-269. 


\title{
WORDS AND MUSIC \\ INTERSECTIONS IN THE WORK OF FERNANDA DE CASTRO
}

\begin{abstract}
In this research, the involvement of the author and poet Fernanda de Castro (1900-1994) in musical creation is investigated. Drawing on the concept of sociability, this article discusses the context of her artistic output in music during the Estado Novo regime in Portugal. This output is identified, described, and characterized, and an analysis of the associated intersection between music, text, and gender is proposed.
\end{abstract}

\section{Keywords}

Twentieth century Portuguese music. Estado Novo regime in Portugal. Women and music. Fernanda de Castro. 